\title{
Performance characterization of high-strength steel and quenched and tempered steels and their joints for structural applications
}

\author{
Martina Aguiari $^{1}$ (D) $\cdot$ Marco Palombo $^{2} \cdot$ Cesare Mario Rizzo $^{1}$ \\ Received: 12 February 2020 / Accepted: 14 October 2020 / Published online: 29 October 2020 \\ (C) The Author(s) 2020
}

\begin{abstract}
Although in the last decades the applicable regulations for the design of steel structures have been deeply improved accounting for modern design approaches and technologies, in a few industrial fields, concepts and formulations derived from centuries-old experience are even nowadays the governing rule. This very often limits the potential offered by the technological innovations in high-performance material, such as quenched and tempered (QT) steels. After having verified in the scientific literature, in the commercial one and in several open material databases that some main data necessary to the comprehensive characterization of QT steel used in building large metal structures are lacking, an extensive experimental campaign was undertaken to achieve an updated and specific fatigue strength characterization for certain types of materials. The aim is to overcome the strict requirements of current regulations on the application of both parent QT materials and welded homogeneous and heterogeneous joints between different steel strength. The experimental campaign allowed filling the knowledge gap as well as providing further understanding whether the use of high-strength steel is effective in the improvement of performances of large steel structures, whose fabrication procedures are typical of building sites rather than workshops. Their extensive application in current building practice is expected to be highly beneficial in terms of weight and costs.
\end{abstract}

Keywords QT steel $\cdot$ High strength $\cdot$ Low alloy steel $\cdot$ Characterization $\cdot$ Fatigue strength $\cdot$ Experimental tests

\section{Introduction and motivation of work}

The use of high-strength steel (HSS) is becoming more and more common since these materials allow lighter, slender and simpler structural designs. In general, the use of HSS contributes to weight reduction, which compensates their higher cost [1].

Recommended for publication by Commission XIII - Fatigue of Welded Components and Structures

Martina Aguiari

martina.aguiari@edu.unige.it

Marco Palombo

marco.palombo@iis.it

Cesare Mario Rizzo

cesare.rizzo@unige.it

1 University of Genova, Polytechnic School, DITEN, via Montallegro, 1, 16145 Genoa, Italy

2 Italian Institute of Welding, Lungobisagno Istria, 15, 16141 Genoa, Italy
The use of HSS, coupled with advanced production technologies, has high potential for weight reduction in welded structures. However, due to the lack of knowledge about fatigue strength and behaviour under dynamic loading more in general, the current rules of regulatory bodies, such as the classification societies in the shipbuilding field or Eurocode for large civil constructions, do not yet allow to take advantage of the full potential of HSS in the design of lighter steel structures [2].

Basically, steel structural design depends on three design and technological constraints, in addition to the satisfying functional and operational needs of the final product:

- Strength (strength to static, dynamic, cyclic, impulsive loads, etc.)

- Stiffness (allowable deformation of the product and limits for elastic buckling)

- Maintenance of performance over time (corrosion and more generally performance degradation)

These design constraints depend on the mechanical properties of the materials and on the geometrical layouts of the 
structure. Generally, the material selection and the design of the structure are combined to be in compliance with the codes requirements.

In order to obtain different stiffness of the structure, it is necessary to take actions either on its geometrical configuration, still satisfying the operational and functional needs of the product (e.g. varying the thickness of the plates or adopting stiffeners of different cross-sectional properties or even modifying the structural layout). In case of large structures, steel continues to be the most widely adopted material and welding the mostly used joining technique.

However, once the steel strength is selected, while the elastic properties are ranging in a rather narrow range (e.g. steel, aluminium or composite materials), the tensile properties have a rather limited effect on the stiffness of the structure.

The problem of corrosion and degradation is usually addressed by designers with the adoption of an oversizing margin in line with recommendations of scantling rules. Typically, thicknesses of plates and reinforcement sections higher than those assessed at the design stage are adopted; therefore, the degradation phenomena are included in the design considering the results of the statistical analyses of the inservice data obtained from monitoring and inspection of similar structures.

Depending on the selected steel strength, the mechanical characterization can exhibit a wide variation: to give an example, the yield stress of steel can vary from $235 \mathrm{MPa}$ of mild steel (typically adopted for normal constructions) to $1100 \mathrm{MPa}$ of HSS (adopted for particular cases).

A similar argument applies to the fatigue resistance of the material, although uncertainties in this respect are definitely much higher and problems for welded structures are also related to technological joining processes that alter the mechanical characteristics of the material and, locally, also the geometry of the area where fatigue fractures typically occur.

Many investigations, beginning from the 1960, have researched the influence of yielding and ultimate strength on fatigue strength of parent material and welded specimens. Several investigations have been performed about 50 years ago when fatigue tests were gathered and statistically evaluated as comprehensively reported, e.g. in [3-7], where several references about this issue are also cited and discussed.

Basically, the designer has a significant flexibility to meet the structural requirements by selecting HSS and tuning thicknesses and cross sections to meet the structural strength requirements of the structure. In fact, often, this freedom, as well as other design constraints, is limited by regulations still anchored to the use of "traditional" steel, such as EN 10025-2 Grade S235 and Grade S355. Their mechanical properties are considered relatively well-known and affected by limited uncertainties, in particular as far as fatigue strength and ultimate strength associated to collapse buckling phenomena are concerned.
The solution of adopting a stronger steel to cope with high tensile stress states is therefore not easily practicable for the designer in current practice, and consequently it is necessary to select alternative solutions such as redesign structural details geometry or use thicker insert plates in critical areas.

From a general point of view, these solutions involve the following disadvantages:

- Increased engineering hours

- Increased fabrication hours

- Increased number of welds and, consequently, more heat affected zones (HAZs)

The adoption of an HSS would reduce or eliminate these inconveniences.

Another aspect that must be considered is related to the cost of HSS in the design and manufacturing of welded structures. In general, market analysis using data available in the literature has shown that the price per tonne of QT steel is higher than that of conventional steel: $900 \div 1500 € / t$ and $650 \div 800$ $€ / t$, respectively.

The assessment of the economic impact related to the use of HSS cannot just be limited to the cost per unit of weight of the material because several other aspects must be considered such as:

- Lower thicknesses imply a reduced quantity of steel for the same structure.

- Reduction of the number of inserts with increased thickness to reinforce the areas with high stresses concentrations. Often, in openings corner or in way of discontinuities of plated structures, an insert of increased thickness is added in order to reduce the stress level and to improve the fatigue strength. If the whole structure or a large part is made by higher strength steel, there is less need of such inserts.

- Reduce warehouse costs due to the lowered use of high thickness plates for the inserts.

- In general, high reduction of management, maintenance and repair costs.

In the scientific literature, there are several materials online databases ([8-14]) showing the main characteristics of the building material and, in particular, for several types of steel.

In general, the databases classify the various materials in terms of productor/seller and in terms of mechanical characteristics versus steel type. Those lists are useful because they allow to:

- Identify the productor/seller of material

- Identify the classifications according standard rules, e.g. ASTM or ISO standards 
- Assess the availability of the products for the construction (thickness of plates, stiffener profiles, etc.)

- Assess the availability of any data of mechanical characterization, possibly to be confirmed only by few dedicated tests by designers

- Quickly compare different materials with similar characteristics

- Obtain a rough estimate of the cost

Design codes like Eurocode 3 [15] do not show explicit dependency on material, which implies significant safety margins. In general, HSS is still seldom investigated, leading to lacking of understanding of their strength and fatigue behaviour. Many fatigue studies are actually focused on testing structural details rather than investigating the plain material behaviour, e.g. [16].

Several studies are focused on the analysis of the base material, such as De Jesus et al. [17] that compared the fatigue behaviour of EN 10025-2 Grade S355 and EN 10025-6 Grade S690 steel strength. Carvalho et al. extended the study reported in [17] to a wider range of structural steel, namely, to the S235 steel [18].

Lillemäe-Avi et al. [19] investigated the fatigue strength of high-strength steel. The study includes both EN 10025-2 Grade S355 and EN 10025-6 Grade S690 steel strength and focuses on the influence of surface roughness, internal inclusions, hardness and residual stress field on the fatigue strength.

No other comparison data on welded joints between different steel strength have been found in open literature.

Therefore, an extensive campaign of experimental tests has been conducted to obtain updated values to be compared with those reported in the design codes (e.g. EN 1993-1-3: Eurocode 3: Design of steel structures [20] or classification societies rule, such as the ones of the International Association of Classification Societies [21] and related individual rules for shipbuilding) for the mechanical characterization in fatigue conditions for the following materials:

- The ferritic-perlitic steel EN 10025-2 Grade S355 (steel A), widely used for structural applications

- Two quenched and tempered steel strength having yield strength between 400 and $500 \mathrm{MPa}$ (steel B, S460) and 600 and $700 \mathrm{MPa}$ (steel C, S690)

Those materials have been examined both as base material and welded joints in different combinations (homogenous joints and heterogeneous ones). In particular, butt welds full penetration joints have been made on plates 10 and $20 \mathrm{~mm}$ thick and a cruciform joint made of $20 \mathrm{~mm}$ thick plates.

Table 1 shows the complete list of the prepared specimens highlighting the combinations of different materials (homogenous joints and heterogeneous ones), the type and welding techniques and the thickness of the plates. Homogenous joints have not been made using steel $\mathrm{C}$ because they are currently considered of limited application interest. On the other side, the heterogeneous joints with steel B have been realized, as it is often necessary to adopt inserts with increased thickness to strengthen high stress concentration areas.

All the specimens were made using the welding processes typically used on building sites (i.e. submerged arc welding, SAW and flux cored arc welding, FCAW), thus replicating the operating conditions used during fabrication and actually being made by qualified welders on site as parts for a construction.

Each weld of the three steels was basically performed in the same way currently used for the Grade S355 steel A and hence with no preheating and no post-welding heat treatment as long as usual workshop welding procedures rather than laboratory ones were aimed at. In short, specimens were actually built by workshop welders using normal procedures, equipment and techniques of large welded structures fabrication in view of the application of steels B and C during construction without substantially modifying the working process. Welding parameters were selected according to standards (UNI EN ISO 15614-1:2017) as previously mentioned. The cited standard does not report welding parameters, but independently from fabrication procedure, it recommends tests for weld joint qualification, which were satisfactorily carried out to qualify steel $\mathrm{B}$ and steel $\mathrm{C}$ welding processes. Hardness measurements, micrographs and other qualification tests were independently carried out by the steel construction company, and their results and full details of the welding procedure approval are unfortunately not available, being considered confidential in commerce. However, all welds were in compliance with quality level B of ISO 5817, and hardness measurements were in compliance with ISO 15614 standards.

Butt and fillet welds between homogenous/heterogeneous joints have been welded using plates of the same thickness and with the adoption of jigs to minimize shrinkage.

All the specimens were tested in the as welded (AW) condition.

\section{Planning of the experimental campaign}

After summarizing the motivations of this work in the introduction, the planning of the experimental campaign is described in the following. The aim of this work was to obtain a data set to be used within construction practice. Hence, experiments were planned to satisfy the needs of the designers and to overcome the limitations introduced by the regulations, which imply overconservative safety factors when the information about the material characterization are not available. Indeed, designers often rely on S-N curves based on tests carried out up to 2 or 5 million cycles, while for modern 
Table 1 List of the prepared and tested samples ( $B W$ butt-weld plate, $F W$ fillet weld) and cruciform joint

\begin{tabular}{lllll}
\hline Combination of materials & Welding type & Plates dimension $[\mathrm{mm}]$ & Welding technique & Thickness [mm] \\
\hline Steel A/steel A & BW & $2000 \times 600$ & FCAW & 20 \\
Steel B/steel B & & $1200 \times 800$ & SAW & 10 \\
& BW & $2000 \times 600$ & FCAW & 20 \\
Steel A/steel B & BW & $2000 \times 600$ & SAW & 10 \\
& & $1200 \times 800$ & FCAW & 20 \\
Steel A/steel C & BW & $2000 \times 600$ & SAW & 10 \\
& & $1200 \times 800$ & FCAW & 20 \\
Steel B/ steel B & FW & $2000 \times 400$ & SAW & 10 \\
\hline
\end{tabular}

high-strength materials, such criteria could not match with the real behaviour of these steels.

The following experimental tests have been planned for base material and for welded joints, previously qualified according to UNI EN ISO 15614-1 to confirm the possibility of practical implementation in current workshop practice, [22].

\subsection{Long-life fatigue test of parent material}

The purpose of these tests is to estimate the well-beyond-theusual-life fatigue strength of the material.

Usually, fatigue strength data are available in scientific literature for high-strength steel, with typical tests carried out up to a few million cycles, as confirmed by the bibliographic analysis carried out before the execution of the tests [8-12, 23, 24].

However, it seemed useful, in addition, to confirm those data and to obtain a first-hand fatigue characterization of highstrength steel materials, to exploit the possibility of having strength data even in the range of tenths of million cycles to confirm or possibly to revise the traditional extrapolation adopted for S-N curves. Fifty million cycles have been selected as run-out limit of this test since one hundred million cycles is a typical target life for many structures like ships and offshore structures or some civil structures. Considering the marine structures, the value of $1 \mathrm{E}+8$ cycles is related to an average life of 25 years subjected to a cyclic loading, induced by the waves of the sea (at about $0.1-0.2 \mathrm{~Hz}$ ).

Fifty million cycles run-out limit was eventually selected as a compromise between testing feasibility and actual structural behaviour, taking into account that in reality, structures are subject to variable amplitude loading. Moreover, it was of interest to understand what actually happen to QT steels at a very high number of cycles, as there are very limited available and up-to-date data in open literature.

Rotary bending fatigue strength tests were carried out up to 50 million cycles on tests specimens made by steel A, steel B and steel C. A series of at least 15 specimens was tested for each material (Fig. 1).
The tests were carried out with the classical prototype equipment shown in Fig. 2. Three out of the six used machines are shown. Rotating four-point bending test of a cylindrical specimen fitted with suitably tapered conical ends was carried out by applying constant force by means of calibrated springs. The load ratio was obviously equal to $R=-1$, and the midspan of the specimen was loaded by constant bending and therefore constant stress range, whose application frequency depends on the applied spring force. During the test at different load levels, the load application frequency ranged between 40 and $45 \mathrm{~Hz}$.

The cross section of each specimen has a nominal diameter of $7.5 \mathrm{~mm}$, and the constant bending specimen span is $25 \mathrm{~mm}$. However, for the determination of the stress level, the actual diameters of each specimen tested was measured by means of a calliper whose accuracy was $0.02 \mathrm{~mm}$.

For the determination of the number of cycles to failure, the complete fracture or the deformation of the specimen making rotation impossible was considered. In fact, the latter criterion corresponds to cracks with a depth of about half the diameter or more. As mentioned, a test limit (run-out) of several million cycles (50 million, except in a few cases) to investigate the fatigue phenomena in a range reasonably related to that of structures in operation. When the run-out limit of 50 million cycles was reached, the test was interrupted, and the test of the same specimen restarted at a higher load level.

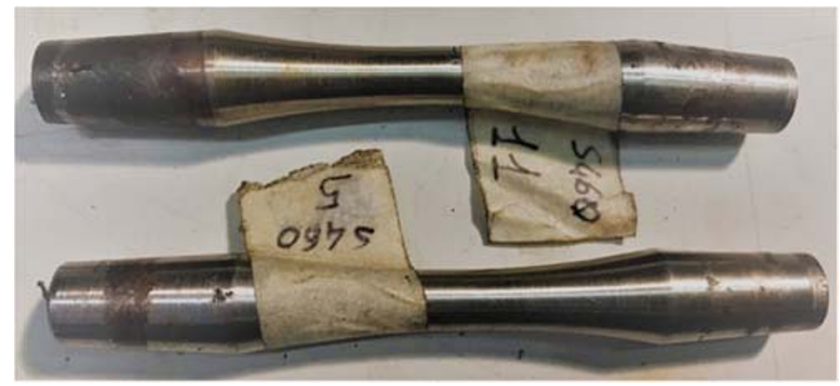

Fig. 1 Two specimens of the tested series (steel B) 


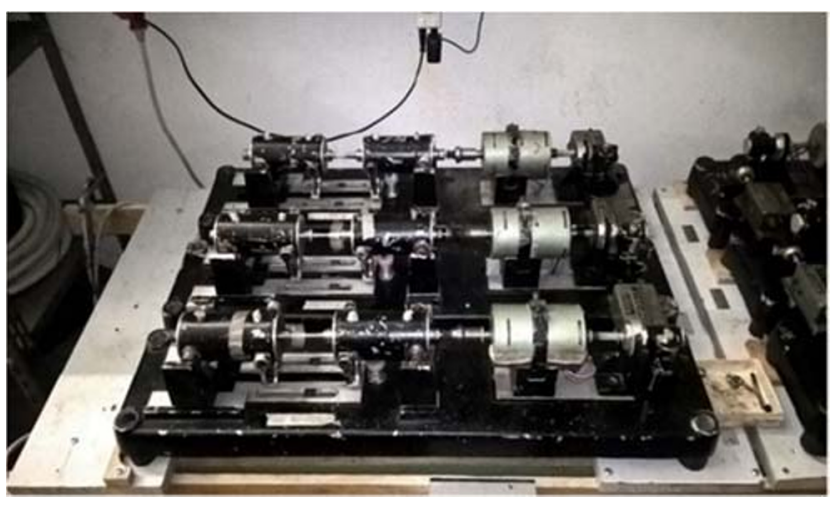

Fig. 2 Rotating bending test machines (3 out of 6 shown)

\subsection{Fatigue test on butt-welded joints and a cruciform joint}

The fatigue tests on welded joints were carried out on typical standardized dog bone specimens with weld reinforcement (no flushing of the welds). In Fig. 3, a sketch of the specimens, an overview of two ruptured specimens, a butt-weld and cruciform specimen, is shown after the fatigue test. Figure 4 shows a 10-mm-thick cross-weld specimen after the fluorescent magnetic particle test to reveal the crack at the weld toe.

Carefully applying the recommendations of the International Institute of Welding [IIW document XIII-214016 , [2]] for the performance of fatigue test on welded joints, the width of the specimens was maintained equal to three times its nominal thickness $(60 \mathrm{~mm}$ for the $20 \mathrm{~mm}$ thick specimens and $30 \mathrm{~mm}$ for those $10 \mathrm{~mm}$ thick). The head of the specimens has been holed to allow them to be properly aligned and clamped to the testing machine in case of relatively high applied loads.

The tests were carried out using a resonance electromechanical machine, under load control and with a load application frequency ranging between $85 \div 90 \mathrm{~Hz}$. The load ratio used for the whole test campaign was conservatively maintained at $R \leq 0.1$. For the determination of the number of cycles to failure, the complete fracture of the specimen was considered.

For each test batch, 12 to 15 specimens were prepared and tested; when the run-out limit of 5 million cycles was reached, the test was interrupted and the test restarted at a higher load level. Similarly to parent material tests, the stress applied on each specimen was calculated by measuring the actual thickness and width of the plate on the specimen taken from the butt test pieces. On the cruciform specimens, the weld throat height was measured on all four-corner seams, and then the strength section was calculated by multiplying twice the average weld throat height by the width of the specimen. Hence, the loadcarrying cross section area was duly considered by using the throat thickness to obtain the acting nominal stress.

\section{Results of the fatigue tests}

In order to show the differences and analogies between a traditional steel such as the steel $\mathrm{A}$ and the steel $\mathrm{B}$ and steel $\mathrm{C}$, for both base material and welded joints, the diagrams of the obtained results are shown and commented in the following.

The data have been analysed according to the recommendations of the International Institute of Welding [2]; hence, the run-out tests (interrupted tests) were normally excluded from the statistical analysis.

Figure 5 shows the results obtained for the base material with a fatigue life up to 50 million of cycles. Noticeably, the slope trend is rather high with respect to the one suggested by steel construction standards [2]. While up to 2 million cycles, the rule slope is $m=3$, beyond it is equal to 5 , but experimental one is higher than 10 .

The experimental data on homogenous joints are shown in Fig. 6. The angular misalignment corrections according to the formulae of the International Institute of Welding, namely, as recommended in Appendix 6.3 of ref. [2] for angular misalignment between flat plates (fixed ends), have been applied to the test data. The data corrected considering the angular misalignment were labelled with the suffix "corr." in each plot. Actually, misalignment was measured on all specimens before testing them. Therefore, data have been corrected in order to additionally show test results excluding the misalignment effect and thus allowing further comparisons and usage of the obtained S-N curves.

There are no differences in fatigue strength between the analysed materials, and the dispersion band is convincingly very limited. However, the angular misalignment introduces a slightly worsening effect in fatigue strength on steel B.

The heterogeneous joints results data are shown in Fig. 7, and if compared with the behaviour of the homogenous joints, no substantial differences were exhibited in fatigue strength; indeed, the experimental data are all in rather limited dispersion band, although a bit larger than the curves in Fig. 6. In this case, a reduction of the fatigue strength of about $11 \%$ can be observed.

In Fig. 8, a diagram is shown to highlight the fracture side in each heterogeneous butt-weld; the diagram considers just the specimens that reached the rupture (no run-outs) on the welds where the steel A is joined to the steel B and steel A is joined to the steel C. Weld quality of all joints was basically very similar. Most of the ruptures occurred at the weld toe on the steel A side; because of the lower tensile properties of this steel, such result could have been hypothesised initially but could not be given for granted before the tests. On the other hand, the scientific literature and the regulations tend to agree that the fatigue strength does not vary substantially for steel with different static strength.

Conversely, the result obtained for the base material, shown in Fig. 5, where the fatigue strength of the steel $\mathrm{C}$ is 
Fig. 3 Top: Sketch of welded specimens. Bottom, from left to right: Butt-welded $20 \mathrm{~mm}$ specimen after the test and detail of fracture initiated at the weld toe; cruciform joint fractured at the root after the test (fracture location highlighted by the arrow)
Butt-weld test specimens
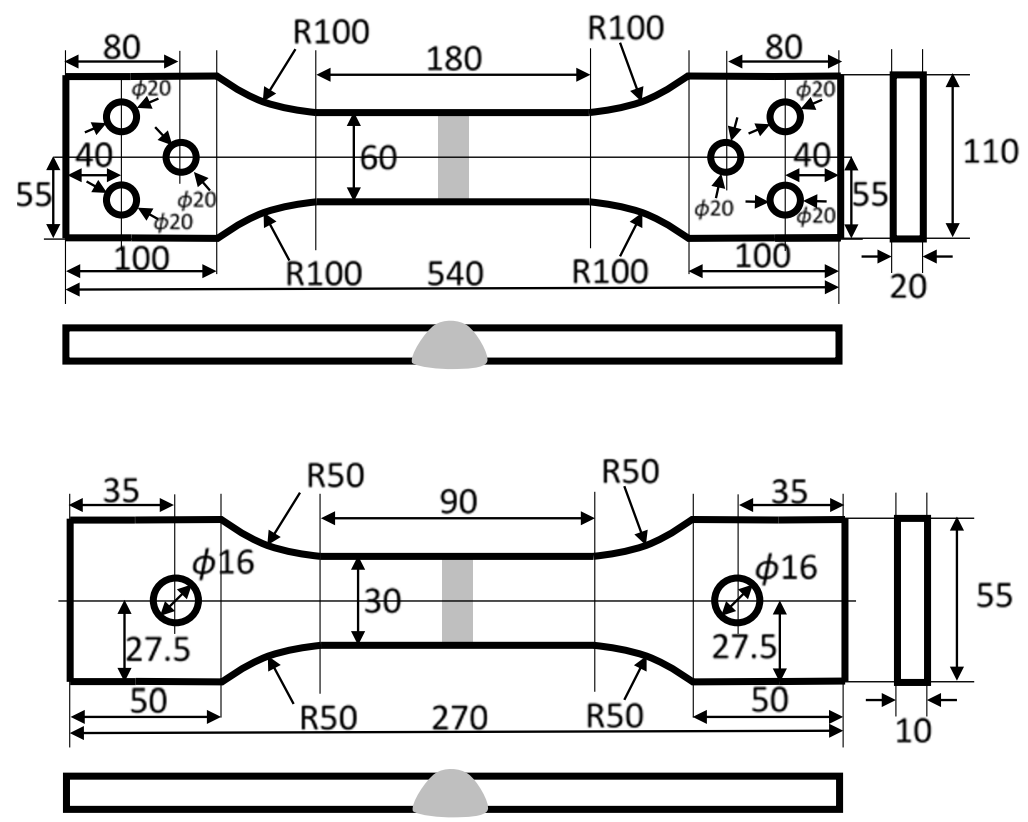

Fillet-weld (cross) test specimen
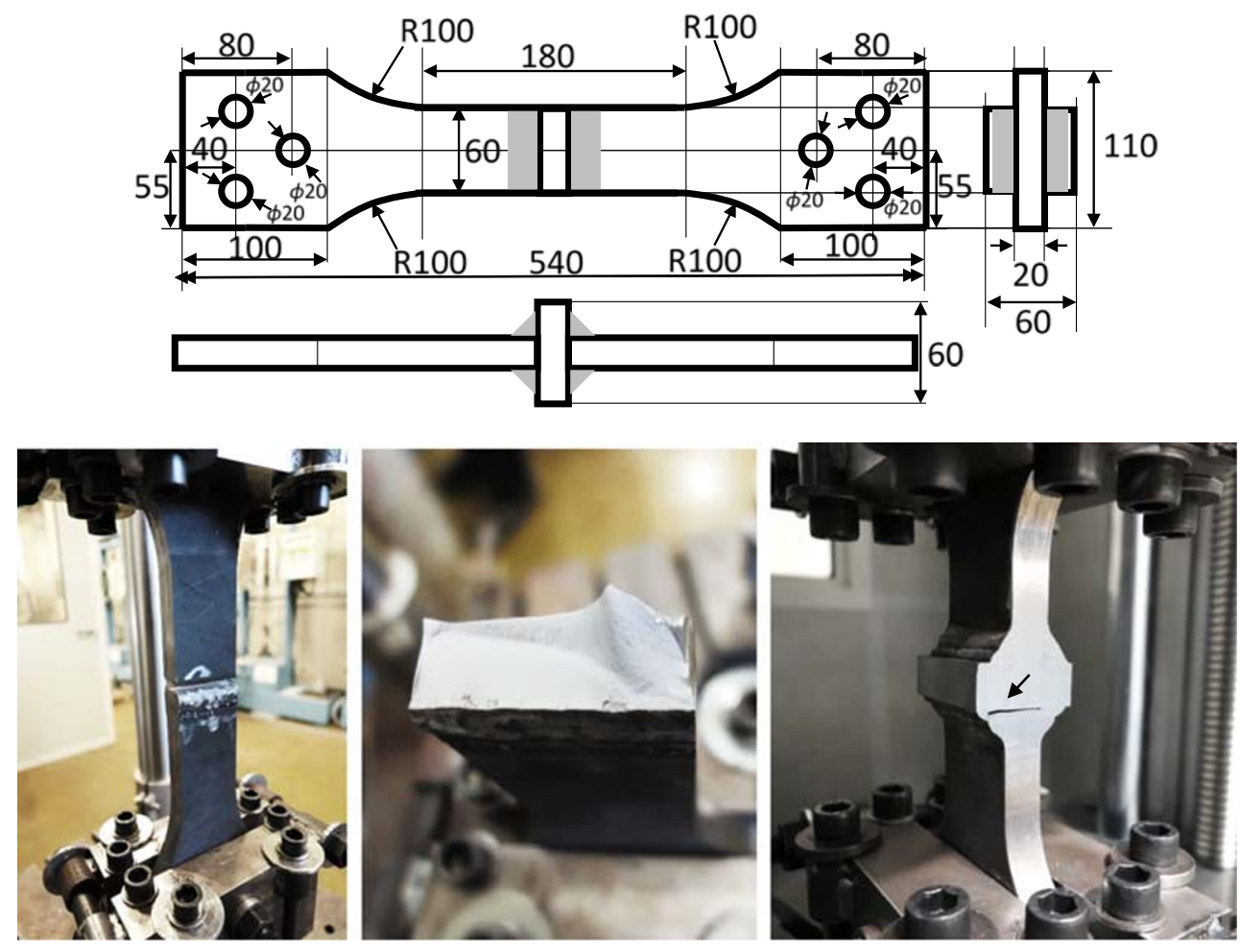

higher than that of steel A and the steel B, seems to be confirmed.
Moreover, the heterogeneous joints do not seem to influence in a different way the strength of the various materials. 


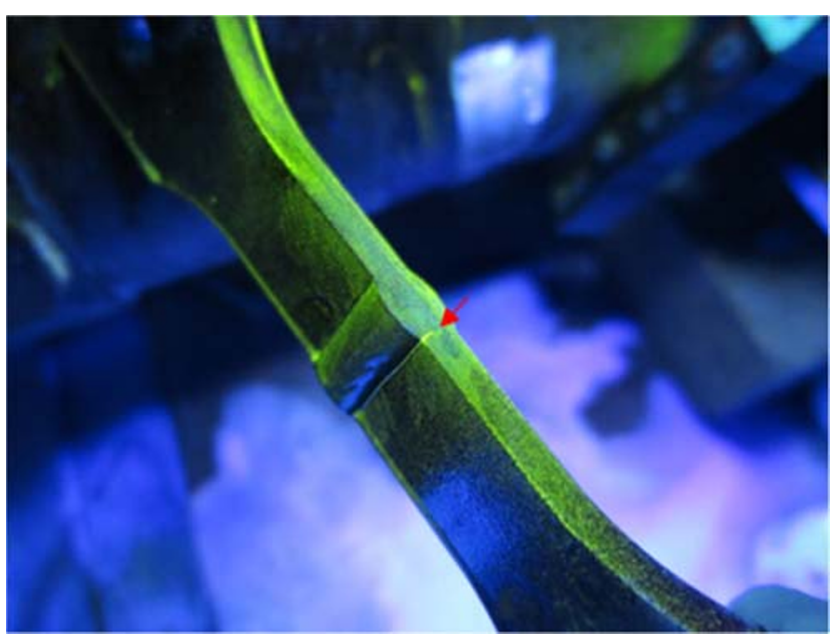

Fig. 4 Butt-weld 10-mm-thick specimen after the fatigue test; fluorescent magnetic particle test to reveal the crack at the weld toe (the crack is highlighted by a red arrow)

Figure 9 shows the fatigue tests results on a cruciform joint made by steel B. The dispersion band is still rather limited, witnessing good data consistency. A smaller number of runouts show that the welding process and the local geometry of the joint have a significant impact onto the fatigue strength, even more than the material properties. Nominal stress was defined as the applied force divided by the load-carrying cross section area of the specimen, i.e. considering the actual weld throat thickness. Average value of the throat thickness of the four welds of each joint was evaluated. Negligible deviations were found, and the overall average (all specimens) was $9.99 \mathrm{~mm}$.

Figure 10 shows in the same diagram all the tests carried out.

The tests on the base material were carried out with a load ratio equal to $R=-1$ while those on welded joints with a load ratio equal to $R=0.1$. In addition, the tests were performed at different loading conditions: rotary bending fatigue tests were conducted on the parent material while axial fatigue tests on welded joints.
In order to make a direct comparison, the data relevant to the parent material have been corrected to shift them from $R=$ -1 to $R=0.1$, according to [2] as mentioned.

As regards the different loading condition applied, reference was made to the results obtained by Amirian et al. [25]: in this study, HSLA100 steel was analysed both in axial tension and rotary bending loading condition, and the results showed a difference of about $13 \%$ between the two tests. This percentage difference was applied to the base material.

Figure 10 allows evaluating the effect of the welding process on the fatigue strength and that of the different geometry of butt and cruciform joints. It is important to underline that the data obtained lead to slopes of S-N curves of the base material $(m>10)$ similar to all steel strength and considerably higher than that of welded joints $(m \sim 4)$. Noticeably, slopes are increasing from fillet weld cruciform joint (FW) to butt-weld joint (BW), to parent material specimens, as expected.

Figures 11, 12, 13 and 14 show the S-N curves of the welded joints (homogenous and heterogeneous) highlighting the influence of the welding technique used to build the specimens (submerged arc, SAW and flux-cored arc welding, FCAW). In general, there are no substantial differences depending on the welding technique and the thickness, as shown in Fig. 15 where all data are gathered (without run-outs).

Figure 15 shows all the experimental data obtained from welded joints and base material. As explained in Fig. 10, the base material data have been adjusted to take into account the different load ratio and the different load condition applied. The data obtained from the tests on base material specimens were compared with the work of Lillemäe-Avi et al. [19].

All the data are also compared with the curves suggested by the Eurocode EN 1993-1-9 for the detail category FAT 90 (butt-welded full penetration, rough finish), FAT 36 (corner welding normally stressed with respect to the flange) and FAT 160 (for rolled or extruded products with machined edges, seamless hollow sections). According to paragraph 6.7.2 of [2], FAT 36 and FAT 90 have been lowered at 2 million cycles by $20 \%$ making them steeper to allow for the greater effects of residual stresses.
Fig. 5 Fatigue teste results on base material

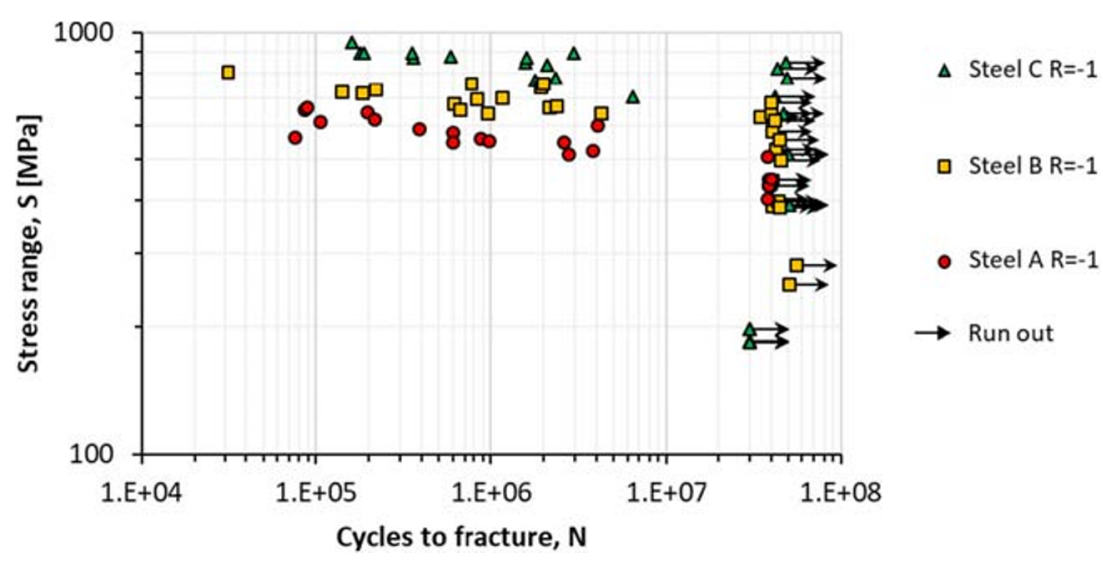


Fig. 6 Results obtained from fatigue tests on butt-weld homogenous joints made of steel A and of steel B. The data are asrecorded and re-evaluated considering the angular misalignment effect according IIW recommendations [2] (data labelled with suffix "corr.")
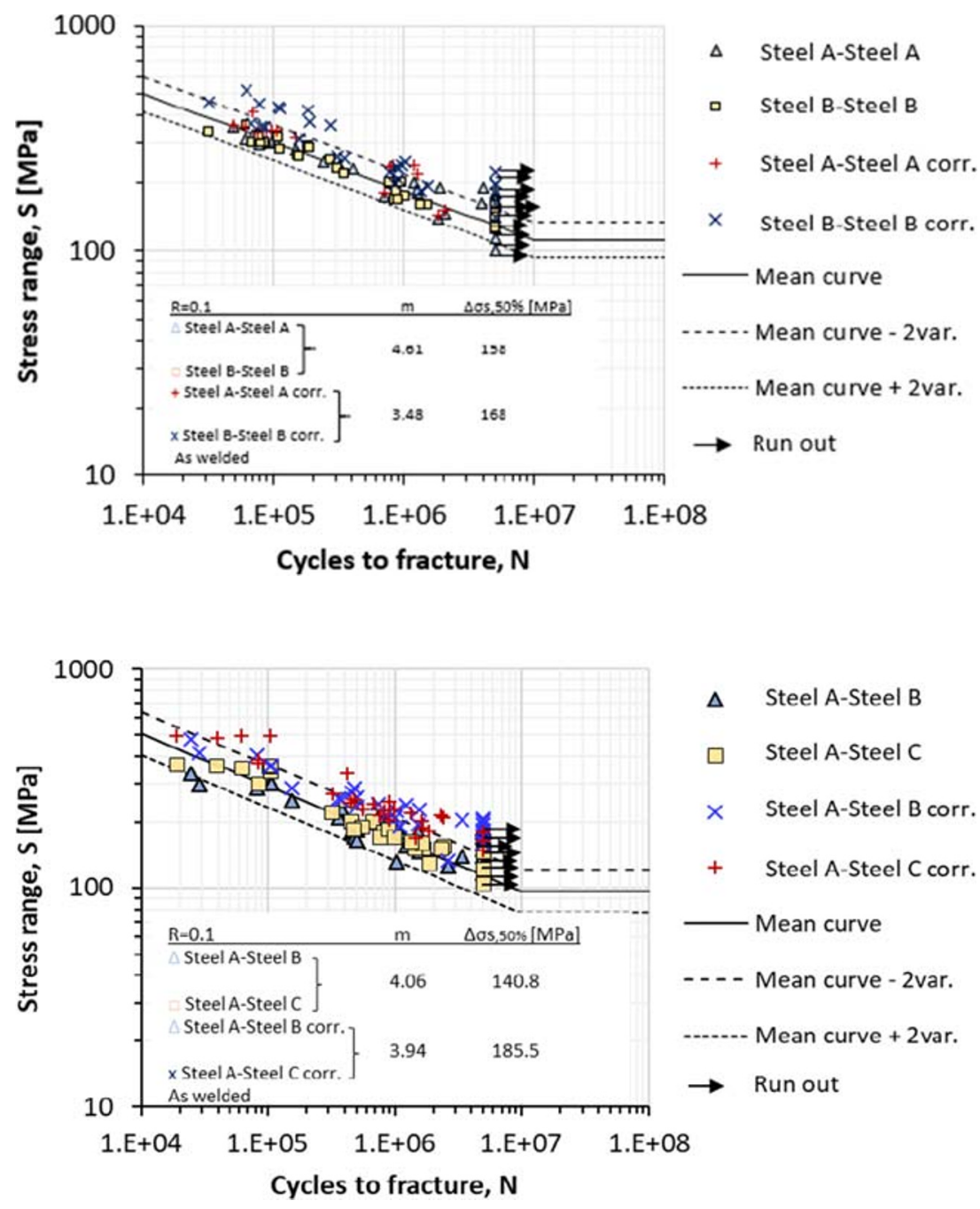

Fig. 7 Results obtained from fatigue tests on heterogeneous butt welding full penetration joints between steel A and steel $\mathrm{B}$ and between steel A and steel C. The data are as-recorded and reevaluated considering the angular misalignment effect according IIW recommendations [2] (data labelled with suffix “corr.")
However, the FAT 90 curve shows a different slope with respect to the experimental data by overestimating the fatigue life in the low-cycle field (below a fatigue life of $1 \mathrm{E}+5$ cycles) and predicting an underestimated fatigue life for applied stresses around the fatigue limit ( 2 million of cycles).
Comparing FAT 36 curve with the data obtained from the tests conducted on the cruciform joint, it is shown that expected behaviour of the Eurocode for this type of joints is rather conservative, while the slope of the curves is very similar up to 5 million of cycles.

\begin{tabular}{|l|c|}
\hline $\begin{array}{l}\text { Failed specimens per heterogeneous } \\
\text { joint }\end{array}$ \\
\hline Steel $A$-Steel $B$ & 22 \\
\hline Steel $A$-Steel $C$ & 24 \\
\hline $\begin{array}{l}\text { Fatigue failure locations on } \\
\text { heterogeneous joints per steel strength }\end{array}$ \\
\hline Steel $A$ & 34 \\
\hline Steel $B$ & 5 \\
\hline Steel $C$ & 7 \\
\hline $\begin{array}{l}\text { Percentage of fatigue failures locations } \\
\text { on heterogeneous } \\
\text { strength }\end{array}$ \\
\hline Steel $A$ (34 on 46$)$ & per steel \\
\hline Steel $B$ (5 on 46$)$ & $11 \%$ \\
\hline Steel $C$ (7 on 46$)$ & $15 \%$ \\
\hline
\end{tabular}

Fig. 8 Fracture position percentage ratio in steel A-steel B and steel A-steel C heterogeneous joints 
Fig. 9 Results obtained from the cruciform joint made with steel B with nominal thickness of $20 \mathrm{~mm}$ and nominal weld throat thickness of welding of $10 \mathrm{~mm}$. The data are as-recorded and re-evaluated considering the angular misalignment effect according IIW recommendations [2] (data labelled with suffix "corr.")
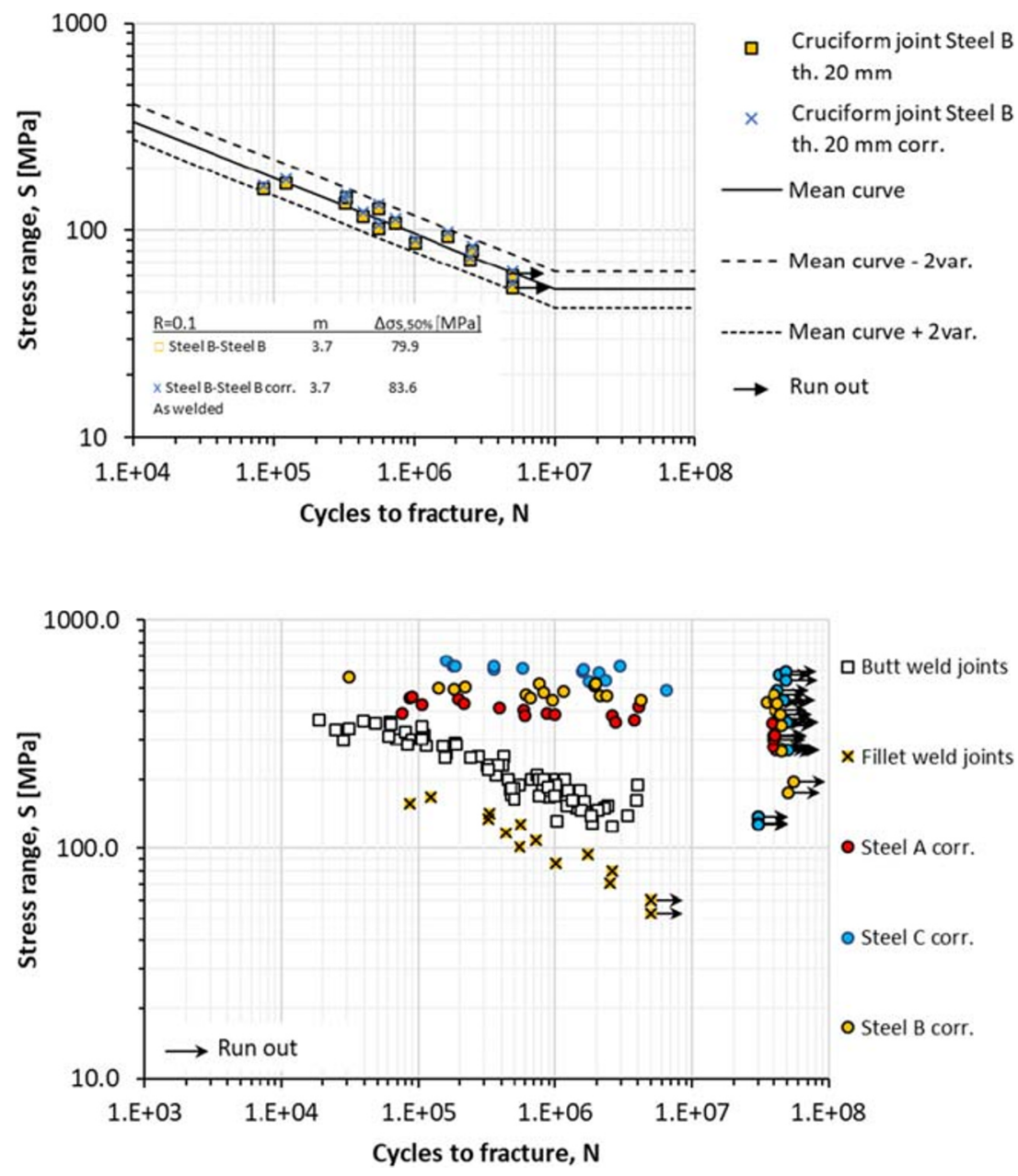

Finally, the FAT 90 curve is well superimposed to the experimental data in the middle between these two zones.

The base materials appeared as aligned with the recent data of the literature [19]; in fact, from a qualitative point of view, the same slopes of the curves were obtained.

The average slope of the S-N curves is $m=4.2$ for the experimental data against the typical $m=3.0$ value suggested by the Eurocode and by various other regulations up to 2 or 5 million cycles.

\section{Conclusions}

This paper experimentally investigated the fatigue strength of two high-strength quenched and tempered steel having yield stress between 400 and $500 \mathrm{MPa}$ (steel B) and 600 and $700 \mathrm{MPa}$ (steel C) and, typically, used in large and heavy steel construction. For comparative purposes, the same experimental tests were also carried out on a more common steel (ferriticperlitic steel EN 10025-2 Grade S355), named steel A.
Fig. 11 S-N curves of the homogenous butt joints steel Asteel A using different welding technique. The data are asrecorded and re-evaluated considering the angular misalignment effect according IIW recommendations [2] (data labelled with suffix "corr.")

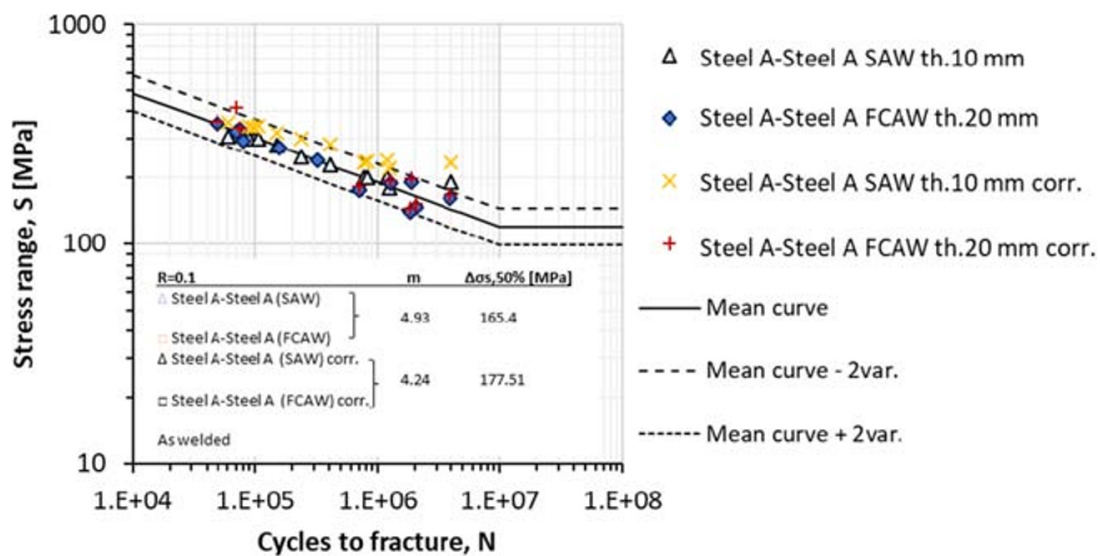


Fig. 12 S-N curves of the homogenous butt joints with steel $B$ grade steel using different welding technique. The data are as-recorded and re-evaluated considering the angular misalignment effect according IIW recommendations [2] (data labelled with suffix "corr.")
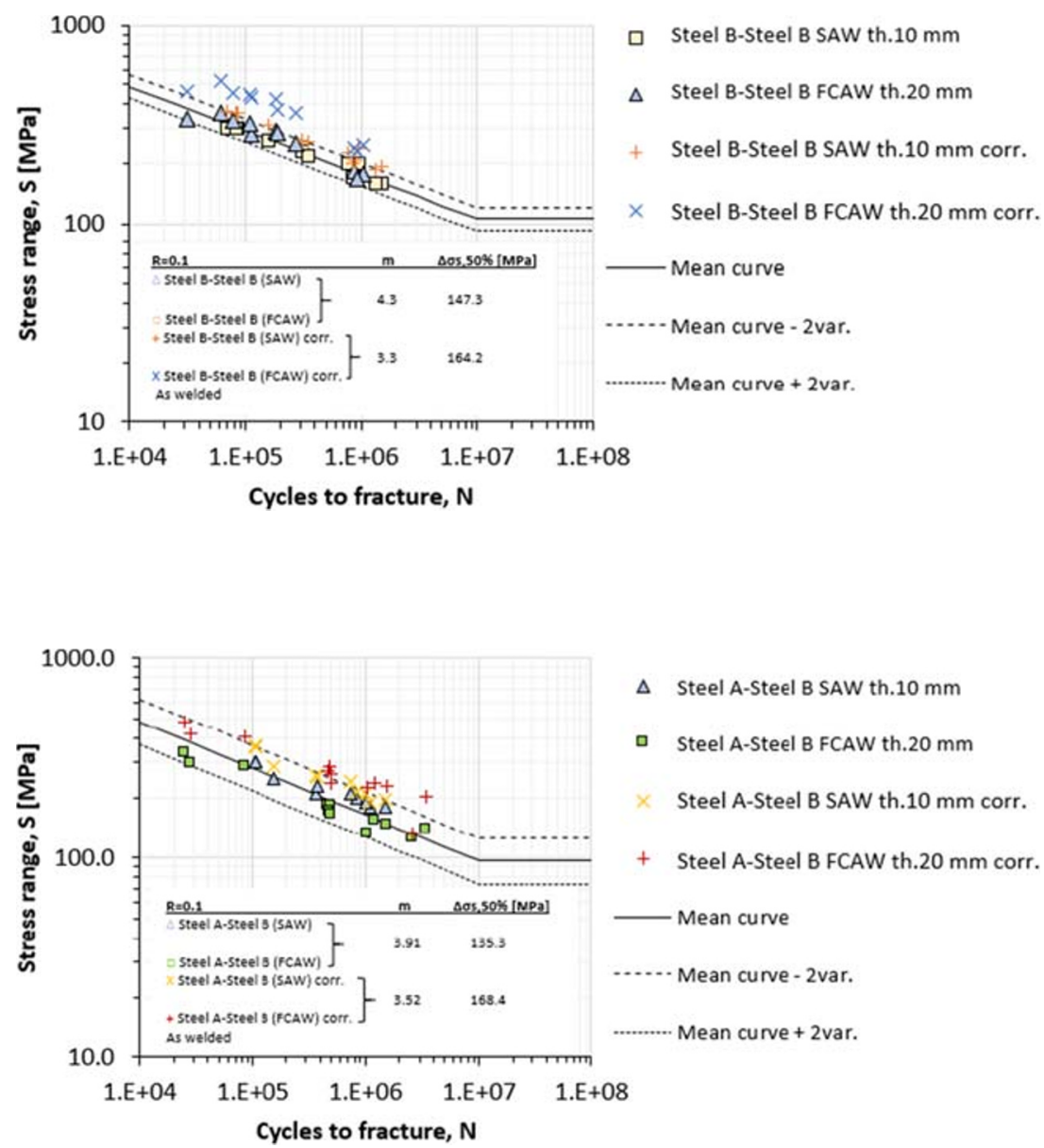

Particular attention was paid to the fatigue strength of the material for which the available information was very limited, dated or not fully available in open literature [17-19].

Based on the results obtained, the following conclusions can be drawn:

- The fatigue test results on the base material confirmed that the higher the tensile strength of the material is, the higher the fatigue strength is; therefore, the following ranking was confirmed: steel C and, then, steel B and steel A.
- The results obtained from the heterogeneous joints (A-B and $\mathrm{A}-\mathrm{C})$, as well as the homogenous joints (A-A and B-B), confirm the possibility to use the high-strength steel for the construction of certain parts of the product, i.e. those more stressed, for which the larger economic effort is justified.

- Slopes of S-N curves for the base materials were found, qualitatively, larger than the conventional slope $m=3$; this result is highly beneficial for fatigue strength assessment and is in compliance with the results reported in the literature $[19,26,27]$.
Fig. 14 S-N curves of the heterogeneous butt joints with steel A-steel C using different welding technique. The data are as-recorded and re-evaluated considering the angular misalignment effect according IIW recommendations [2] (data labelled with suffix "corr.")

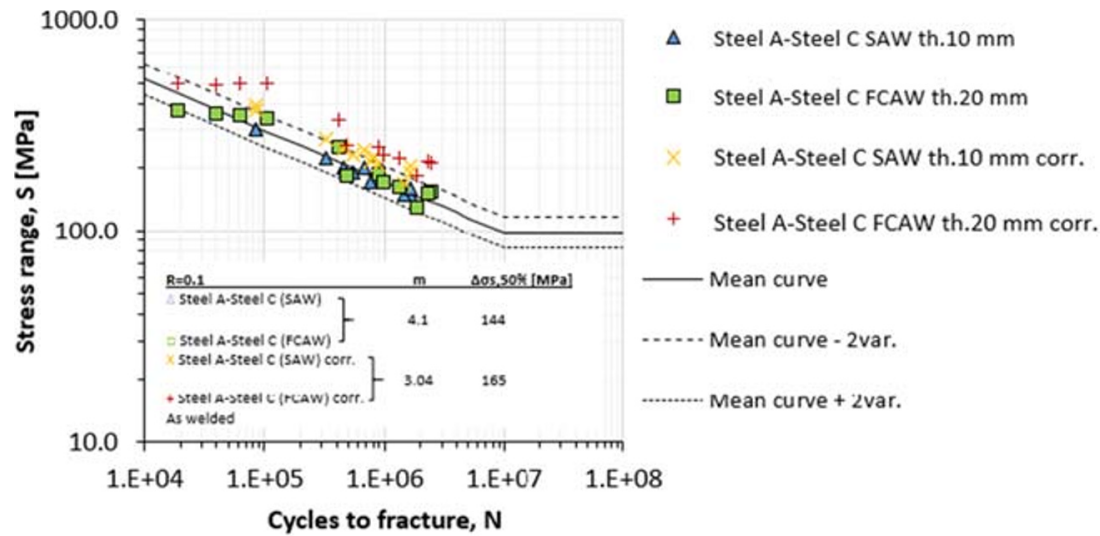


Fig. 15 Comparison of the results obtained for the base material steel $\mathrm{A}$ and for the steel $\mathrm{B}$ and steel C (corrected from $R=-1$ to $R=0.1$ and from bending fatigue to axial fatigue) and the fatigue test results obtained for buttwelded joints and cruciform joints with the corresponding fatigue strength curves indicated by IIW and Eurocode [20], i.e. FAT 112, FAT 90 and FAT 36, respectively. FAT 90 and FAT 36 are also shown corrected according to paragraph 6.7.2 of [2].

Comparison of test results with those reported in [19]

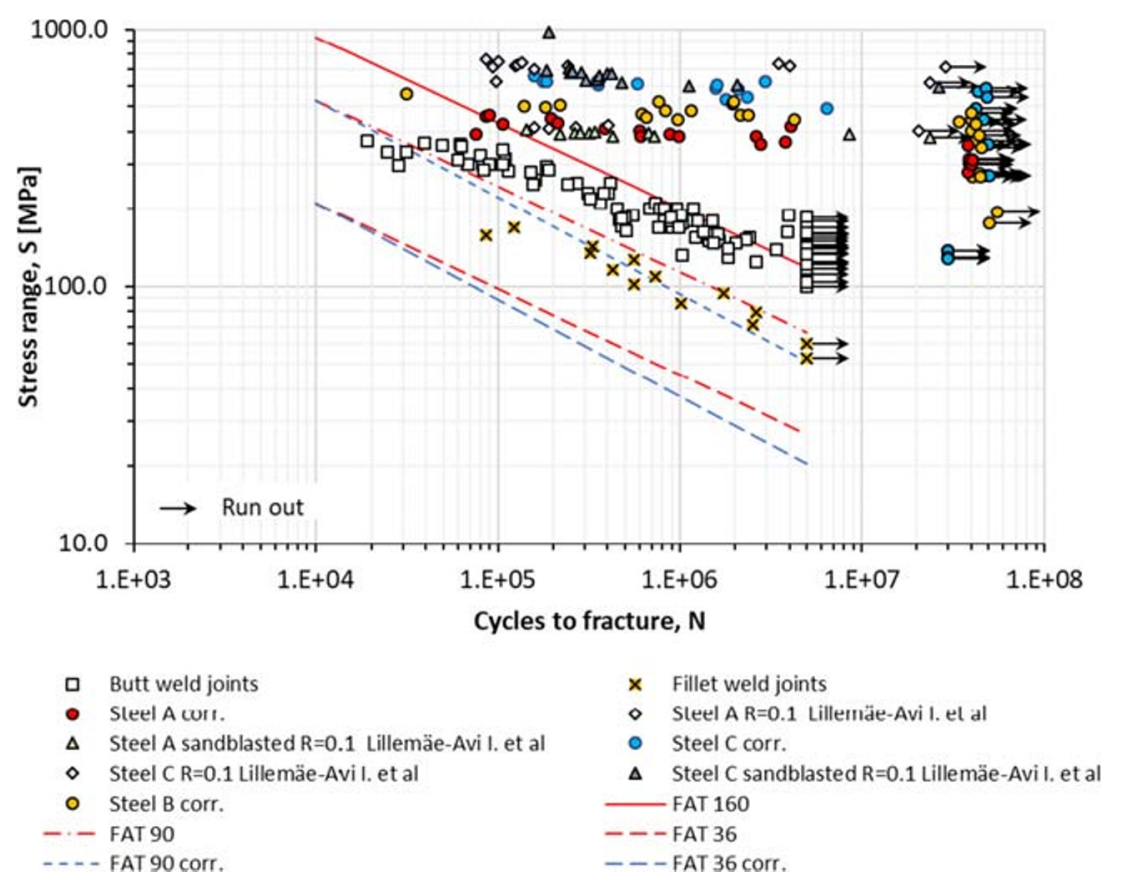

- There are no substantial differences on butt-weld joints, and this confirms the independency of fatigue strength from the tensile strength of metallic materials as stated by scientific literature and regulations.

- Although the S-N curve of heterogeneous butt-welded joints did not differ substantially, it is worth noting that most of the cracks in the HAZ occurred on the steel A side of the specimen $(74 \%)$, while the percentage of ruptures on the side of the other steel strength is much more limited ( $11 \%$ in steel B and $15 \%$ in steel C, respectively). It can be argued that, in case of steel A welds, residual stresses are relatively more influencing being the material yielding point lower, hence creating higher cyclic straining. Therefore, expected failure position in heterogeneous joints is that of the lower material strength.

- It was found that tested QT steels can be welded by applying the same welding processes currently applied for more common steel strength such as steel A in yards or on site, i.e. without pre-heating and special post-welding treatments, without substantially modifying their fatigue strength behaviour. This implies saving cost and complexity of the operation and increase the productivity.

- It should be borne in mind that the limit states linked to structural stiffness are generally satisfied by modifying the structural layout and the structural element geometries (i.e. thickness and cross sections) because the different types of steel offer relatively similar elastic modulus values.

- It can be seen that the cost saving of reducing the used material, as an increase in strength leads to a general reduction of the thicknesses, must always be compatible with what is permitted by the phenomenon of buckling, which could become the limit state governing the design.
Stress analysis methods permit to extend the results of tests on simple geometry to complex structural details by numerical calculation and then to analyse complex details such as the one presented in [16].

Eventually, it is believed that the data presented in this paper are ready to use for design purposes and can be further analysed to develop and validate fatigue assessment approaches by researchers of the field.

Acknowledgements Open access funding provided by Università degli Studi di Genova within the CRUI-CARE Agreement.

Open Access This article is licensed under a Creative Commons Attribution 4.0 International License, which permits use, sharing, adaptation, distribution and reproduction in any medium or format, as long as you give appropriate credit to the original author(s) and the source, provide a link to the Creative Commons licence, and indicate if changes were made. The images or other third party material in this article are included in the article's Creative Commons licence, unless indicated otherwise in a credit line to the material. If material is not included in the article's Creative Commons licence and your intended use is not permitted by statutory regulation or exceeds the permitted use, you will need to obtain permission directly from the copyright holder. To view a copy of this licence, visit http://creativecommons.org/licenses/by/4.0/.

\section{References}

1. Sperle J-O (1997) High strength steel for optimum structural performance. SSAB Tunnplåt $\mathrm{AB}$, Borlänge

2. Hobbacher A (2016) Recommendations for fatigue design of welded joints and components, 2nd edn. Springer, Heidelberg

3. Milella PP (2000), Fatigue and corrosion in metals, Springer-Verlag Italia ISBN 978-88-470-2336-9 
4. Juvinall RC (1967) Engineering considerations of stress, strain and strength. McGraw-Hill, New York, p 214

5. Boyer HE (Editor), atlas of fatigue curves, ASM International

6. ASM Handbook, (1996) Volume 19 - fatigue and fracture, ASM International. Handbook Committee, ISBN 0-87170-385-8

7. Schijve J, (2009) Fatigue of structures and materials, Springer, eISBN-13: 978-1-4020-6808-9

8. ASM Material Information. http://mio.asminternational.org. Accessed 10 Jan 2020

9. Total Material. http://www.totalmateria.com. Accessed 10 Jan 2020

10. Matweb. http://www.matweb.com. Accessed 10 Jan 2020

11. Material Properties Database. https://www.makeitfrom.com. Accessed 10 Jan 2020

12. Matmach. https://matmatch.com. Accessed 10 Jan 2020

13. ASTM G59:(2014) Standard Test Method for Conducting Potentiodynamic Polarization Resistance Measurements

14. Metallic Material Database (Kinzoku). http://metallicmaterials. nism.go.jp. Accessed 10 Jan 2020

15. UNI EN 1993-1-9:(2005) Eurocode 3: Design of steel structures Part 1-9 Fatigue

16. Rizzo CM, Tedeschi RA (2007) Fatigue strength of a typical ship structural detail: tests and calculation methods. Fatigue Fract Eng Mater Struct 30:653-663

17. De Jesus AMP, Matos R, Fontoura BFC, Rebelo C, Da Silva LS, Veljkovic M (2012) A comparison of the fatigue behavior between S355 and S690 steel grades. J Constr Steel Res 79:140-150. https:// doi.org/10.1016/j.jcsr.2012.07.021

18. Carvalho D, Silva ALL, Jesus AMP, Fernandes AA (2015) Fatigue behaviour of structural steel - comparison of strain life and fatigue crack propagation data. Mecânica Experimental, Vol 25:67-78

19. Lillemäe-Avi I, Liinalampi S, Lehtimäki E, Remes H, Lehto P, Romanoff J, Ehlers S, Niemelä A (2018) Fatigue strength of high- strength steel after shipyard production process of plasma cutting, grinding and sandblasting. Weld World 62:1273-1284. https://doi. org/10.1007/s40194-018-0638-y

20. UNI EN 1993-1-9:(2005) Eurocode 3: Design of steel structures Part 1-1: General rules and rules for buildings

21. International Association of Classification Societies, Unified Requirements on Material and Welding UR W, http://www.iacs. org.uk, IACS, London UK

22. UNI EN ISO 15614-1:(2017) Specification and qualification of welding procedures for metallic materials Welding procedure test - Part 1: Arc and gas welding of steel and arc welding of nickel and nickel alloys

23. Matdat. http://www.matdat.com/. Accessed 10 Jan 2020

24. European Steel and Alloy Grades/Numbers http://www. steelnumber.com

25. Amirian J, Safari H, Shirani M, Moradi M, Shabani S (2017) Assessment of different methods for fatigue life prediction of steel in rotating bending and axial loading, J. Comput Appl Res Mech Eng 6(2):57-68

26. Fischer C, Fricke W, Rizzo CM (2016) Fatigue tests of notched specimens made from butt joints at steel. Fatigue Fract Eng Mater Struct 39:1526-1541, ISSN 8756-758X. https://doi.org/10.1111/ ffe. 12473

27. Fischer C, Fricke W, Rizzo CM (2016) Review of the fatigue strength of welded joints based on the notch stress intensity factor and SED approaches. Int J Fatigue 84:59-66. https://doi.org/10. 1016/j.ijfatigue.2015.11.015

Publisher's note Springer Nature remains neutral with regard to jurisdictional claims in published maps and institutional affiliations. 